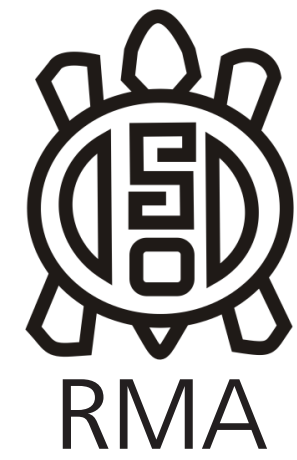

Dossier

\title{
Como o Narrador e a Língua Estruturam o Mito: as Interferências no Conto Bakairi "A Onça e o Tamanduá"
}

\author{
How Narrator and Language Structure Myth: Interferences in \\ "The Jaguar and Tamanduá, a Bakairi Tale
}

Evandro Bonfim

Pesquisador do Centro Brasileiro de Análise e Planejamento, Bolsista Fapesp. E-mail:evandrobonfim@hotmail.com

\begin{abstract}
Resumo
O objetivo do texto é retomar a proposta de análise estrutural desenvolvida por Lévi-Strauss a partir da linguística sem excluir os idiomas nativos e os narradores dos mitos como elementos fundamentais para o estabelecimento de unidades de sistema, chamadas no presente artigo de cosmoemas. Os cosmoemas abordados aqui são fruto da comparação entre duas versões da história Udodo Pajika, contadas pelos Bakairi, povo Karib Sul, de modo a se sobressair a língua, o narrador e a lógica do mito que conferem os sentidos mais amplos dos quais se deve valer o antropólogo interessado nas narrativas nativas.
\end{abstract}

Palavras-Chave: Mito; Língua; Análise Estrutural; Narrador, Karib

\begin{abstract}
The paper aims to revisit the structural analysis proposal developed by Levi-Strauss based on the a Linguistics model, however not excluding the native languages and the narrators of myths as key components to find out system units, called cosmoemas in this article. The cosmoemas covered here are the result of comparison between two versions of the story Udodo Pajika, told by Bakairi, a Karib South people, in order to focus on how the compound language, narratorand logic of the myth give the broadest sense of narratives which must be worth anthropologist interested in native process of story-telling.
\end{abstract}

Keywords: Myth; Language; Structural Analysis; Storyteller, Karib

A obra de Lévi-Strauss, sobretudo a série Mitológicas e livros posteriores como A Oleira Ciumenta e História de Lince, constitui-se o maior empreendimento antropológico de definição e apreciação dos aspectos fundamentais da arte narrativa que chamamos mito, tomando como caso exemplar as mitologias dos povos ameríndios. No entanto, a análise estrutural, abordagem utilizada pelo autor tomada de empréstimo à Linguística, tem estado em desuso por vários motivos.

Em primeiro lugar, poucos antropólogos mostram se sentir a vontade com conceitos e procedimentos primeiramente linguísticos (mas também de outras fontes como a matemática e a psicanálise) cujo entendimento exige maior aproximação com as fontes originais de outras disciplinas menos preferíveis, por exemplo, ao recurso à filosofia. Em segundo lugar, a Antropologia atual se apresenta como vivenciando "viradas" (ontológica, material, pós-estruturalista), que embora se construam em oposição à "virada linguística" representada de maneira clara pelos procedimentos analíticos Lévi-straussianos, não pode deixar de lado a questão da linguagem e da alteridade linguística'.

No entanto, à exceção do próprio Lévi-Strauss, o veio estruturalista parece efetivamente pouco explorado como forma de tratar etnograficamente fenômenos da linguagem como as narrativas mitológicas. Gostaríamos de recuperar a inegável riqueza da análise estrutural para tratar de enredos míticos dos Bakairi, povo de língua Caribe Sul que vive no Brasil Central, estado de Mato Grosso. A retomada dos princípios estruturalistas vai procurar incluir fatores considerados acessórios para o pensamento Lévi-straussiano no que diz respeito à análise mítica: a língua e o narrador, os quais, no entanto, são elementos constituintes da oralidade própria à cosmologia Bakairi.

A fim de mostrar como a língua e o narrador podem

\footnotetext{
${ }^{1}$ Em alternativa, estudos como a Pragmática e nomes como Pierce, Austin e Searle estão cada vez mais presentes nas etnografias e propostas reflexivas sobre o conhecimento antropológico, subsumido os fatos linguísticos a determinados fenômenos isolados da configuração sistêmica das línguas.
} 
estruturar o mito, o presente trabalho combinará análise estrutural com dados etnográficos e linguísticos, tanto coletados em primeira mão quanto provenientes de obras clássicas sobre os Bakairi². A exposição se divide em três partes, começando pelos comentários do próprio Lévi-Strauss sobre os dois fatores "extra míticos". Depois, tomando como mito de referência o conto sobre as escaramuças entre a onça e o tamanduá (Udodo Pajika), tais observações serão confrontadas com fatos da língua Bakairi evidenciados pela narrativa mítica que mostram a relevância de instâncias como o fonema e o morfema para a proposição das unidades sistêmicas do mito, como zooemas e mitemas. Então, se destacará as interferências do narrador do mito na história contada, apresentando traços de reflexividade e distanciamento que sugerem pontos de fuga da armação mítica. Tais discussões apontam para a importância do conhecimento da língua e das distintas locuções dentro do mito para a etnografia da linguagem mitológica.

\section{Língua e Narrador no projeto de análise mitológica estruturalista}

A exclusão do componente linguístico é de suma importância para o projeto de análise estrutural desde a análise dos termos de parentesco. Seguindo a proposta de Kroeber (1909), Lévi-Strauss aponta como crucial a diferença entre terminologia e sistema de atitudes de parentesco, a fim de que predomine a pesquisa do fato social atual no lugar da busca incerta por origens de instituições cuja existência não é atestada, mas apenas sugeridas por termos que agregariam posições de parentesco distintas. A ênfase na sincronia provém da formulação do problema linguístico por Saussure, que se questiona sobre a língua efetivamente falada ao invés da ênfase histórica dos estudos filológicos.

Para se chegar às questões propriamente mitológicas, como afirma Lévi-Strauss em "A Estrutura dos Mitos", é necessário proceder como a ciência linguística, que estabelece níveis diferentes de análise através da distinção entre parole e a langue, o domínio da estrutura. Embora pensado como linguagem, no sentido de que lança mão das mesmas operações do pensamento presentes nos sistemas linguísticos, o autor preconiza como condição da análise estrutural antropológica a independência do mito em relação à língua: "O mito está ao mesmo tempo na linguagem e além dela". (...) "O mito é uma linguagem, mas uma linguagem que trabalha em um nível muito elevado, no qual o sentido consegue, por assim dizer, descolar-se do fundamento linguístico do qual inicialmente rodou" (1958a:124-5).

Assim, o autor toma como base a relativa independência

\footnotetext{
O texto a seguir usará as seguintes convenções linguísticas. Elementos entre barras /a/ são unidades do sistema mítico. Elementos entre colchetes são realizações das unidades de sistema [a] ou da língua Bakairi. Traços portados pelos elementos considerados virão entre colchetes com sinais binários atribuídos [+/-].
}

dos níveis de análise da lingüística, que à época do Estruturalismo se concentrava na determinação das unidades de sistema em patamares crescentes de organização do sentido (fonema, morfema, semantema), para propor a noção de "mitema", estabelecido a partir da seguinte divisa: "nada explicar do mito senão pelo mito" (1971:606). Para Lévi-Strauss, a importância dos estudos linguísticos se deve a questão dos aspectos literários das narrativas míticas, como a dimensão poética. Os dados linguísticos, portanto, não interferem no inventário de elementos nem na elaboração dos sistemas míticos. Isto inclui as versões de mitos similares em línguas diferentes, muitas vezes ultrapassando as fronteiras das classificações genéticas. Como não há possibilidade de se chegar à fonte original do mito em meio à quantidade de versões pertencentes a povos distintos, "todo mito é, por natureza, tradução" (idem:624), o que exige a busca pelo sentido do mito em elementos que possam ser considerados invariáveis.

Quanto ao narrador, é precisamente a anulação dele, tanto em termos do indivíduo com a habilidade de contar histórias, que vai suscitar a emergência de determinada forma verbal como mito. "Para passar para o estado de mito, é preciso justamente, que uma criação deixe de ser individual e perca, no transcorrer dessa promoção, o essencial dos fatores que podiam ser atribuídos ao temperamento, ao talento, à imaginação e às experiências pessoais de seu autor" (idem:604). Um ponto menos trabalhado, mas que certamente está embutido no papel que Lévi-Strauss atribui ao narrador como articulador verbal suficiente de enredos que mantém as características principais diante da multiplicidade de variantes, diz respeito ao indivíduo como instância representativa de determinado momento daquela coletividade indígena, que muitas vezes é capaz de produzir interferências na narrativa principal tanto de cunho reflexivo como de maneira mais incisivas, alterando momentos decisivos da mitologia.

\section{O Mito de Referência: Udodo Pajika}

Segundo Lévi-Strauss (1964:224-226), a rivalidade entre o jaguar e o tamanduá (udodo e pajika em Bakairi), é um dos mais difundidos temas míticos sul-americanos, e remetem ao ciclo dos gêmeos míticos sol e lua (Xixi e Nuna em Bakairi). Duas versões da história foram coletadas entre os Bakairi, a primeira por Karl Von den Steinen (1892) com Kuikare, durante as expedições às cabeceiras do Xingu (1884 e 1887) e a segunda cem anos depois por Tania Clemente de Souza (coletada em 1985 com Waluga e publicada em 1999). A versão do explorador alemão contém tradução interlinear e tradução livre para o alemão, enquanto que a versão de Souza integra uma inovadora análise sobre discurso e oralidade em línguas indígenas, mostrando como o sentido emerge das próprias características linguísticas do Bakairi, o que permite ver como a história e a 
cosmologia do próprio povo se inscreve no idioma que falam e em outros lugares de memória. Em sentido analítico, o presente artigo segue no esteio das obras de Souza no que tange à discursividade própria dos mitos Bakairi, presente em trabalhos que inclusive já trataram da narrativa sobre a Onça e o Tamanduá em cotejamento com a noção lévi-straussiana de "sinédoques abstratas" (2008). A diferença temporal entre as duas versões permite a observação de variações linguísticas e modificações em diversos momentos da narrativa que precisam ser levados em consideração por quem faz a análise dos mitos de inspiração estrutural, conforme se está propondo.

O mito consiste na série de situações surgidas pelo encontro entre a onça e o tamanduá, nos quais o último sempre engana o primeiro, com as ações progredindo da jocosidade para a agressão mútua. No primeiro encontro, os dois animais resolvem comparar os excrementos, de modo a demonstrar através de pistas corporais quem tinha a característica mais prezada, a de caçador devorador de carne. O tamanduá propõe que façam o teste de olhos fechados, trocando as fezes a fim de confundir a onça para tentar se igualar a ela.

No segundo encontro eles marcam uma caçada, quando se revela toda a inépcia do tamanduá, algo especialmente evidenciado na versão de Souza que registra as onomatopéias que trazem a informação decisiva a respeito da habilidade dos arqueiros, pois é pelo efeito acústico que se afere tanto a precisão da flecha disparada pelo felino quanto o malogro do tamanduá, cuja seta mal se desprende do arco. A onça consegue matar uma anta, mas é desviada da carne moqueando pelo tamanduá que se esconde em cima de uma árvore para comer a carne. A onça tenta derrubar o tamanduá usando poderes xamânicos como o controle dos ventos.

No terceiro encontro, os amigos resolvem dançar, mas o tamanduá aproveita a ocasião para enfiar as poderosas garras na cara da onça e lhe arrancar os olhos, que outros animais conseguem devolver para o felino. Em represália, a onça morde a perna do tamanduá dando-lhe o formato atual. A principal diferença entre as versões está no desfecho. Em Von den Steinen, a onça abre um presente que o tamanduá deixa na casa dela, cheio de veneno mágico, matando-a. Em Souza, a onça continua tentando perseguir o tamanduá, que, contudo, consegue fugir (1999: 230,31).

\section{Cosmoemas em Kura Itanro}

O próprio título do conto "A Onça (udodo) e o Tamanduá (pajika)" deixa patente quem são os protagonistas da história e quais os termos mais se canditariam à posição de unidades sistêmicas em relação de oposição das duas variantes do mito aqui tratadas. Os Bakairi atuais também são claros em associar o indígena à onça e o tamanduá ao não-indígena (karaiwa) por variadas razões, sendo que é precisamente as diferenças entre os dois a principal base dos engodos que o tamanduá dirige ao felino.

No entanto, a tarefa aqui proposta é chegar a tais unidades analiticamente, de forma dedutiva, tomando como ponto de partida circunscrições, diferenciações, aproximações e classificações efetuadas pela lógica nativa, encontradas em instâncias como a língua. Assim, cumpre saber que traços o Kura Itanro (língua de gente, o idioma Bakairi) atribui aos dois protagonistas do conto mítico.

No que diz respeito à udodo, a palavra pertence a um interessante campo semântico delimitado pelo morfema -do. O constituinte -do é um morfema de derivação nominal, ou seja, produz novos nomes a partir de outros substantivos e adjetivos:

(1) a. yuno (sangue)

b. yuno-do (família)

(2) a. menru (jenipapo)

b. menru-mondo (jenipapos)

c. menru-do-mondo (a gente do jenipapo, os Bakairi da Terra Indígena Santana) jenipapo-pessoa-coletivizador

Como se pode ver pelos exemplos, a derivação promovida pelo morfema -do diz respeito a transformar certas substâncias e qualidades em gente. Haveria, portanto, certa relação metonímica entre a palavra primitiva e a palavra derivada, evidenciada pelo compartilhamento de determinado princípio agora personificado. No entanto, o morfema não realiza apenas derivação, pois serve também de marcador para determinados substantivos como possuindo o traço [+gente] em comparação com outros entes que a princípio deveriam integrar a mesma categoria taxonômica ou nem mesmo contar com o traço [+animado] que está pressuposto no atributo "gente". ${ }^{3}$ Assim, o morfema -do atua como classificador, circunscrevendo o seguinte campo semântico, cujas relações entre os elementos que o compõe só podem ser recuperadas através da informação mítica:

À diferença dos exemplos em (1) e (2), o morfema -do

\footnotetext{
3 A Escala de Animacidade de Silverstein estabelece o traço semântico [+animado] para tratar de fatos linguísticos como o uso e a distribuição do morfema -do tratado aqui, opção adotada pela principal pesquisadora da língua (SOUZA 1999:62). O fato de propormos o traço [+gente] incorpora tanto a noção gramatical de [+animado] como se mostra mais próxima da lógica mítica que subjaz as transformações morfológicas em consideração, unindo, portanto, linguística e etnografia. No entanto, não se considera como válida a interpretação de Capistrano de Abreu (1895) e Meira \& Franchetto (2005:173) que tomam o morfema -do como índice de pluralidade. Trata-se de um equívoco, pois tanto o -do se mostra produtivo na função comentada no texto da mesma maneira que a indicação de pluralidade é feita pelo coletivizador -mondo. O que está em jogo é a própria lógica da língua, que vê como a forma gente do sangue não o indivíduo, mas a família como unidade hematológica.
} 


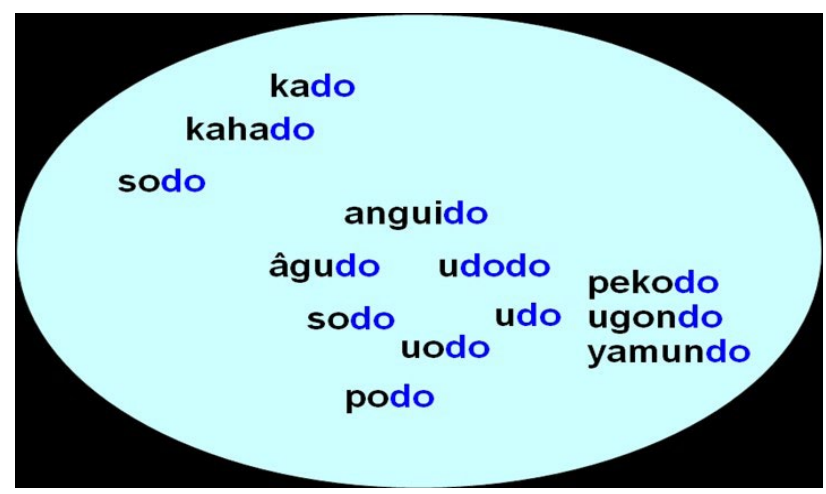

Figura 1. Campo Linguístico-Cosmológico formado pelo classificador-DO*

Figure 1. Linguistic-Cosmological field formed by the classifier-DO

*Tradução: kado (espírito), kahado (banco antropomórfico), sodo (dono ritual), anguido (animal), ângudo (sucuri), udodo (onça), sodo (cadáver animal), uodo (cadáver humano), podo (carne), udo (índio), ugondo (homem), pekodo (mulher), yamundo (criança).

não está ligado aqui à palavras, ou sejas, formas livres que podem figurar na língua sem a necessidade do sufixo. Contudo, tais formas presas remetem a princípios mais gerais que, a bem dizer, ganham consistência com processos de sufixação:

(3) a. peko-do (mulher)

b. peko-baym (hipermulheres)

Pekobaym é o termo Bakairi para o conhecido mito xinguano das Yamurikumã (hipermulheres). Assim, pelos exemplos em (3) pode-se perceber que -do se opõe ao modificador que denota o representante "excessivo" do princípio feminino expresso por peko-4. Mas, como se verá a frente, pekodo possui grande carga mitológica, imprescindível para se entender o termo udodo.

Desta forma, o ponto de partida da análise são os elementos agrupados em áreas de significação a partir de configurações próprias da língua, como a morfologia, e não da elaboração do pesquisador a partir da comparação entre vários mitos. No entanto, a materialidade da língua não informa tudo acerca dos princípios relacionais que agrupam os componentes do campo semântico, sendo necessário reinscrevê-los na discursividade dos mitos onde se podem encontrar processos de semiose não arbitrários como a motivação mitológica e iconicidade cosmológica. Com tal dupla ancoragem, chamamos aqui tais áreas de significação de "campos linguísticos cosmológicos" e os termos que os compõe de "cosmoemas".

A palavra udodo está estreitamente relacionada com udo, índio. Conforme mito contado a mim pelo xamã

\footnotetext{
${ }^{4}$ De acordo com Von den Steinen (1892) peko era um termo de parentesco destinado a irmã em antigas línguas Caribe. Em Bakairi, o vocativo para os principais termos de parentesco leva o sufixo -ko, como seko (mãe), kuko (irmão do pai), tako (avô).
}

(piaje) Vicente Kaiawa, a genealogia Bakairi começa do casamento em que a família das onças exige que Kwamoti entregue uma mulher em aliança. Kwamoti cria filhas das árvores, mas apenas resolve uma resolve se casar, terminando morta pela sogra Mero, mas conseguindo dar luz aos gêmeos criadores dos Bakairi, Xixi (sol) e Nuna (lua). Tudo se passa na época em que não havia luz, quando todos os seres se chamavam anguido, palavra reservada atualmente para os animais.

Assim, udorudodo, pois o indígena Bakairi tem como principal ancestral masculino a onça Oka, nome próprio utilizado como palavra para jaguar em muitas línguas da Família Caribe (por exemplo, akari em Ikpeng). O Bakairi atual se constitui exceção, pois o termo para onça está relacionado com a forma que no Proto-Caribe se refere à pessoa *Witoto. Witoto também é a denominação Caribe para um grupo linguístico inimigo, os Witoto. Em outra língua Caribe Sul, Kuikuro, Itoto significa homem, reforçando a relação entre o atributo masculino e a ascendência dos jaguares que o mito Bakairi coloca de maneira clara, fazendo sentido a oposição [-feminino] udodo:pekodo [+feminino] colocada pelo mito da aliança que origina os Bakairi.

Assim, o significante Caribe Witoto congrega significados completamente afins à lógica ameríndia [jaguar, masculino, gente, indígena, inimigo] que se distribuem de forma diferencial entre as línguas da Família. Udodo, portanto, é a forma magnificada de udo, obtida através da reduplicação do morfema -do. Por sua vez, udo parece ser a personificação do traço [+ primeira pessoa], contido no prefixo absolutivo $u$-, que também é parte integrante do pronome independente urâ (eu).

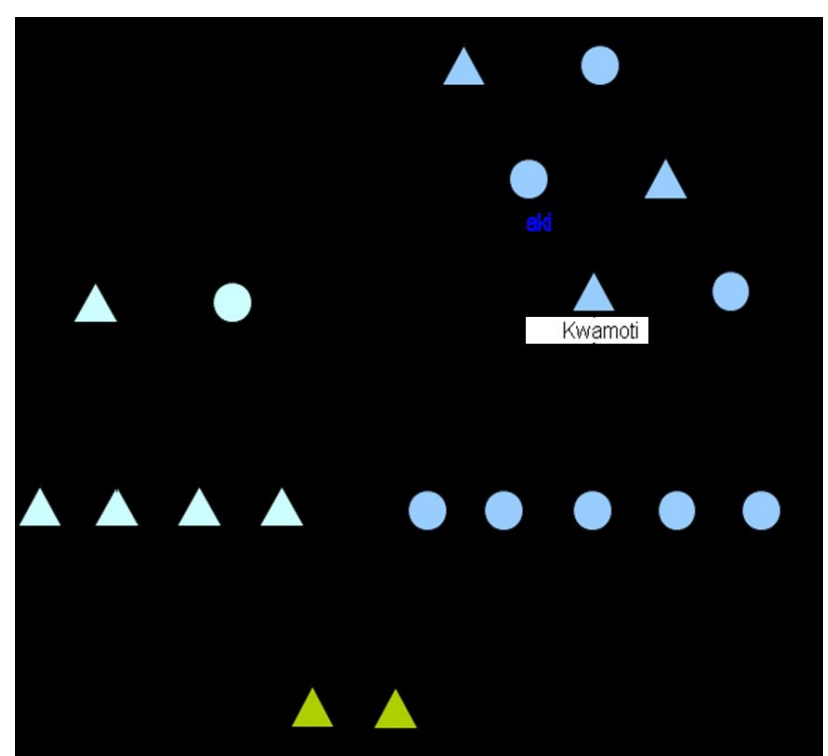

Figura 2. Parentesco Cosmogônico Bakairi (Fonte: Vicente Kaiawa)

Figure 2. Bakairi Cosmogonic kinship (Source: Vicente Kaiawa) 
(4) Udapa

$1 p$ abs-ir-não

"Eu não vou"

Como se sabe desde Benveniste, a primeira pessoa gramatical corresponde à posição enunciativa de locutor, que cumpre função dêitica, não podendo, portanto ser substancializada. Mas no caso Bakairi, tal posição de fala assume realidade ontológica mais ampla que a encerrada nas funções pragmáticas (ver Viveiros de Castro 1996 sobre os pronomes cosmológicos e o caráter pronominal das autodenominações e Bonfim 2015 sobre a categorial pronominal-cosmológica kura no âmbito da própria gramática Bakairi).

Tais feixes de relações, linguísticas e cosmológicas, justificam o estabelecimento de udodo como unidade do sistema mítico Bakairi /udodo/, possuindo como realização contemporânea a própria figura do indígena, [udo]. Dificilmente as traduções /onça/ e /índio/ tem a densidade encontrada na materialidade das palavras Bakairi, que encapsulam toda a potência mítica em sequências sonoras.

No que diz respeito ao pajika, podemos avançar ainda mais na importância da língua para a análise estrutural por proceder a relativização da matriz de traços que Lévi-Strauss constrói usando matemática, língua, mito e música:

Para Lévi-Strauss, o mito apresenta valor negativo para o traço [som] porque "a função significante do mito não se exerce na língua, mas acima dela" (1971:625). Somente quando "a estrutura, descolada do som, adere ao sentido" (idem:624) é que o discurso mítico pode se estabelecer. Contudo, inúmeros fenômenos linguísticos demonstram a impossibilidade de se estabelecer sentidos sem a mobilização de propriedades acústicas das combinações dos sons da fala, como, por exemplo, na entoação. A análise de Souza sobre o Udodo Pajika já traz importantes exemplos reforçando a significância extraída da materialidade linguística, como no caso na

$$
\begin{aligned}
& \text { [-som, -sentido] } \\
& \text { matemática } \\
& \text { MÚSICA } \\
& \text { [+som, -sentido] } \\
& \text { Мाто } \\
& \text { LíNGUA } \\
& \text { [+som, +sentido] } \\
& \text { [-som, +sentido] }
\end{aligned}
$$

Figura 3. Representação da Matriz Som/Sentido de Lévi-Strauss (Fonte: elaboração própria a partir da discussão em Finale, 1971)

Figure 3. Representation of Lévi-Strauss Sound / Sense Matrix (Source: own elaboration from the discussion in Finale, 1971) abundância de onomatopéias e contornos melódicos que correspondem a sequências discursivas inteiras onde o encadeamento de atos é substituído pela pura sonoridade de apelo sinestésico característica das línguas de oralidade (1999:189-203).

Para exemplificar, gostaria de chamar atenção para uma ação do tamanduá que marca a condição dele como figura de alteridade no mito. Trata-se de uma pequena intervenção linguística, uma produção sonora ocorrida durante o momento da batalha xamânica entre os dois bichos, quando a onça tentava derrubar o tamanduá de cima da árvore:

Dizia a onça. - Desce, desce!, mas o outro não obedecia. Aí a onça [nervosa] chamou a ventania. E essa também chamou as formigas:

- Vem, formiga! Vem! Vem, formiga para fazer com que aquele falso comedor de carne desça.

E vieram muitas formigas. Bastante mesmo.

- Ufa! Ufa! - o tamanduá soprava. Ufa! Ufa! - soprava.

Ah, as formigas iam de volta, todas. Então, ele chamou de novo:

- Vem, ventania, vem! Faz aquele falso comedor de carne descer. Vem!

$E$, aí, veio tanto vento de todos os lados, que o céu ficou nublado. E aí começou a chover muito. Aí, sim, era tempestade e vento.

(Versão de SOUZA coletada em 1985)

Em certa ocasião na Terra Indígena Bakairi, aldeia Kaiahoalo, estávamos esperando a festa de aniversário do piaje Vicente, que completaria 90 anos. Enquanto estava sendo assada a carne, nuvens espessas cobriram o céu e se aproximavam cada vez mais do local. O piaje pegou o cigarro próprio dos pajés fazer benzeduras, se coloco contra a direção da chuva e começou a soprar fumaça e o som "ufa, ufa", o mesmo presente no trecho do mito destacado acima. As nuvens pararam antes de chegar ao território principal da aldeia e a água desabou no momento em que os convidados voltavam para casa.

Ufa não é uma palavra da língua Bakairi, mas um ato de fala (sensus Austin). Soprar "ufa" é a ação, não só de benzer, mas também de expulsar elementos indesejados (a chuva, o vento) e animais inimigos, como aqueles que servem de suporte para os espíritos dos mortos, os kadopa. Apesar da importância, tal palavra tem procedência estrangeira na língua Bakairi. Assim como o próprio etnônimo Bakairi, e rituais importantes como Bakururu, certas características na escolha e disposição dos sons evidenciam que tais palavras são empréstimos, e que, mesmo correntemente usadas, continuam portando a marca de alteridade linguística ${ }^{5}$. Ufa se diferencia ainda

\footnotetext{
5 Devido ao fenômeno da harmonia consonantal, que exige a alternância entre consoantes surdas e sonoras na língua (descrito em Souza 1995 e Wetzels 1997), nenhuma palavra Bakairi pode iniciar com consoantes com vibração nas pregas vocais (sonoras). Assim, os termos iniciados pela oclusiva labial sonora [b] atestam a
} 
por não ser pronunciada na chamada fala modal. Todos os segmentos linguísticos ou fones podem ser realizados acusticamente através dos mais diversos tipos de output, sendo a fala regular apenas o mais usual deles. Assobios, silvos através de instrumentos como folhas, tambores, canto e mesmo o sopro são outras formas de expressão sonora das línguas.

No entanto, a marca de [+alteridade] linguística do sopro ufa vem da fricativa lábio-dental [f], que não integra o inventário fonético Bakairi. É sempre interessante lembrar que o som [f] está entre as faltas imputadas à população ameríndia ('sem [f]é, sem lei e nem rei'). Abaixo, a diferença entre os quadros fonéticos no que diz respeito as fricativas comparando a época da coleta de Von den Steinen (1892) com a realizada por Souza (1995):

Em cerca de cem anos, o repertório de fricativas do Bakairi aumentou consideravelmente, principalmente com as variantes combinatórias da glotal aspirada [h]. Contudo, a fricativa [f] permaneceu estática, figurando apenas na ação vocal de benzedura. Ou seja, o som não se incorpora à língua mesmo havendo fenômenos, como a lenição do [p], oclusiva labial que ao se tornar vozeada em espaço intervocálico, se transforma em fricativa labial não registrada por Von den Steinen, ao invés de aproveitar o traço [+labial] de [f]. Assim, embora registrado entre os sons produzidos pelos Bakairi, [f] não pertence ao sistema da língua, podendo ser interpretado como marca de alteridade linguística ${ }^{6}$.

Assim, não parece ser fortuito que enquanto a onça como xamã domina os ventos e as formigas (alimento do inimigo), somente o tamanduá tem posse da fórmula repelente ufa, extremamente impregnada de alteridade, tanto linguística como do saber xamânico, que hoje em dia está ativo no repertório do piaje Bakairi, conforme

proveniência estrangeira, sendo que as palavras "Bakairi" e "Bakururu" provavelmente possuem como origem os vizinhos Bororo.

6 Há casos similares interessantes em outras línguas indígenas brasileiras de segmentos que ocorrem em apenas uma única situação, desviando a atenção do sistema linguístico atual para fenômenos mais amplos como o contato. Quintino (2012:115-122) mostra como a oclusiva velar surda [k] ocorre apenas durante o maior evento festivo xavante, a caçada de fogo $(d u)$, através de gritos de agitação durante a empreitada. O som é completamente estranho ao Xavante, mas, no entanto, remete ao passado linguístico do grupo quando ainda não havia ocorrido a separação entre eles e os Xerente. Trata-se de uma marca de alteridade linguística dentro da variação histórica do próprio Xavante.

(a) Von den Steinen (1892)

$$
\text { f } \quad x(g) \gamma \quad h
$$

(b) Souza (1999)

$$
\text { (p) ß } f \quad x \rightarrow h(g) x \quad h\left[s, z, \int, 3\right]
$$

Figura 4. Quadro Fonético das Fricativas Bakairi

Figure 4. Bakairi Fricatives Phonetic Framework o evento relatado, que combina as potências tanto do udodo quanto do pajika. Portanto, as próprias marcas linguísticas, fonéticas, prosódicas, morfológicas, autorizam a oposição udodo:pajika, cuja atualização contemporânea está na oposição entre o índio (udo) e o não-indígena (karaiwa), i.e., udodo:pajika::udo:karaiwa. Quem fornece tais oposições, além do próprio movimento da análise estrutural, é a configuração da língua Bakairi.

\section{Narrador e Locutor mítico}

Na tessitura dos mitos, geralmente pode-se encontrar diferentes posições enunciativas, que alternam as vozes ao longo da história (Souza 1999:150-158). A inserção discursiva dos locutores nas narrativas míticas depende da forma com que cada língua trata o discurso relatado, tanto do ponto de vista sintático como pragmático, algo que não pode ser confundido com a marcação da evidencialidade, como faz Peter Gow ao falar de "segmento citacional" (2014:190). Para começar, praticamente toda narrativa mítica recebe formas de atestação, pois se trata de uma história proveniente dos antecessores das gerações atuais, ou seja, de pessoas que não estão mais acessíveis para determinação de confiança como fonte de declarações. Novamente, contrariando Gow, o fato em si da atestação não significa necessariamente que o mito possua "caráter dúbio", porque está em jogo não a veracidade do que está sendo narrado, mas cada sistema particular de atribuição de confiança aos responsáveis pelas falas e o comprometimento de quem as reproduz com o discurso direto. Por exemplo, a dupla não atestação em Bakairi (distanciamento do narrador do conteúdo relato) implica na atestação da autoridade mítica, o que corresponde entre os Piro a autoridade do parente próximo em comparação ao parente distante (Gow 2014:192).

No caso Bakairi, a interveniência do narrador, não como Locutor $^{7}$ (aquele que empresta a fala à voz do enunciador mítico), mas como autor, nos termos de Souza (1999, p.156), que interrompe a cadeia de relatos sobre relatos, é que se insere na discussão sobre as possibilidades de estruturação do mito a partir de quem o está contando. Considere as seguintes "interferências" de Waluga, colocadas entre colchetes, na linha narrativa principal de Udodo Pajika (todos extraídos de SOUZA 1999 [1985]):

(5) Aí o tamanduá falou: Vamos lá caçar, vamos matar anta!

\footnotetext{
7 Os termos locutor e alocutário estão presentes nos trabalhos de autores como Benveniste para se referir aos participantes da cena enunciativa e em Ducrot também para as nuances destas participações. O locutor traz as marcas da primeira pessoa enquanto o alocutário representa o outro através da segunda pessoa. No âmbito da discussão de Souza (1999) sobre locutores e alocutários do discurso mítico, o Locutor diz respeito àquele que simplesmente materializa vocalmente a totalidade do discurso mítico, de forma próxima a ideia da função do narrador suficiente de Lévi-Strauss, enquanto o autor, responsável pelos comentários interrompe a cadeia de relatos que vai do Locutor até a pessoa originária que pode relatar o mito de primeira mão.
} 


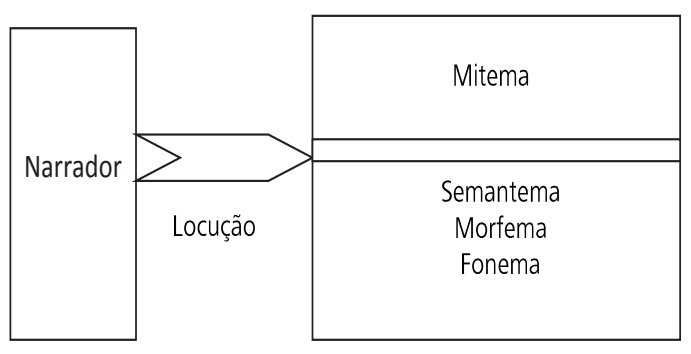

MITO

Figura 5. A Língua e o Mito na Análise Estrutural LéviStraussiana

Figure 5. Language and Myth in Lévi-Straussian Structural Analysis

[Esses tais de tamanduá não comem caça, só cupim. Só onça come caça]

(6) Depois de sarado, eles se reencontraram depois de muito tempo.

[Como são bobos de se encontrarem de novo]

O dado em (5) mostra a tônica dos comentários críticos de Waluga sobre a desfaçatez do tamanduá, que em diversos momentos queria se passar como espécie do mesmo tipo da onça, ou seja, como alguém que tem flecha, sabe caçar, é realmente carnívoro, pois bebe inclusive o sangue da caça, o que no final das contas se revela um estratagema dele para se apropriar do que o felino havia conseguido. Não somente Waluga estava informada das armadilhas do tamanduá, mas inclusive algumas observações sobre as mentiras dele recebem a marca "disseram" (kylemo), mostrando que outros locutores também estavam a par dos fatos.

Tais constatações diferem bastante da versão de Von den Steinen, em que nem o narrador nem os locutores que interferem na narrativa apontam para os ouvintes o caráter deceptivo do tamanduá. Pelo contrário, o narrador permanece silenciado (embora falasse narrando o mito) enquanto as vozes de outros locutores presentes atuam para sugerir ao tamanduá o presente envenenado que extermina a onça. Na narrativa de Von den Steinen há uma passagem preciosa que diz que Oka (o nome próprio da onça) recebe o presente e depois Udodo (nome que representa a espécie) morre, sugerindo o extermínio coletivo.

A fatalidade cede assim espaço para a incorporação de conhecimentos adquiridos por um século de contato entre a onça e o tamanduá. Waluga como indivíduo encarna tal experiência coletiva, visto que nasceu quando as migrações forçadas do Xingu para o Posto Indígena Simão Lopes, atual T.I. Bakairi, ainda ocorriam, e muitos morriam na travessia, de fome e de doenças provocadas pelo contato com os karaiwa, muitas vezes em motivados pela busca dos presentes que os não-indígenas davam.

Assim, a 'necessidade estrutural do Outro' que é mais forte do que o risco de morte como conclui Lévi-Strauss na pequena mitológica História de Lince (1992) como a maior unidade do sistema mitológico ameríndio deve começar a ser matizada por observações como a de Waluga sobre "como são bobos de se encontrarem de novo", principalmente a onça por saber das motivações sempre enganosas do tamanduá. A versão de Waluga fica sem desfecho porque o conhecimento adquirido ao menos pelos indígenas Bakairi ainda não o permitem capturar o tamanduá que vence por conseguir fugir, atualizando as estratégias de lograr a onça.

\section{Conclusão}

Em "A Estrutura dos Mitos", Lévi-Strauss propõe o mitema como unidade constitutiva que está acima das que integram os níveis linguísticos que compõem a narrativa mitológica (fonema, morfema, semantema), sendo mais complexa e inassimilável em relação às precedentes. Além de se situar acima da língua, a substância do mito não pode ser encontrada "nem no estilo, nem no modo de narração" (1958a:.225), ou seja, o elemento narrador está completamente fora do complexo mitológico.

No entanto, conforme demonstrado ao longo do texto, tanto a língua quanto o narrador, este último não como indivíduo - ainda que as capacidades expressivas dos contadores mereçam toda atenção - , mas como representante de determinado momento histórico do grupo indígena, fornecem importantes subsídios para o estabelecimento das unidades constituintes do mito, corroborando informações que podem ser obtidas através da análise estrutural do modelo acima e indo além, conferindo mais profundidade aos elementos invariantes (como na diferença entre o cosmoema /udodo/ e o zooema /onça/) ou mesmo modulando tais invariantes. Assim, a análise estrutural que incorpora a língua e o narrador, sugerida aqui se apresenta a partir não da

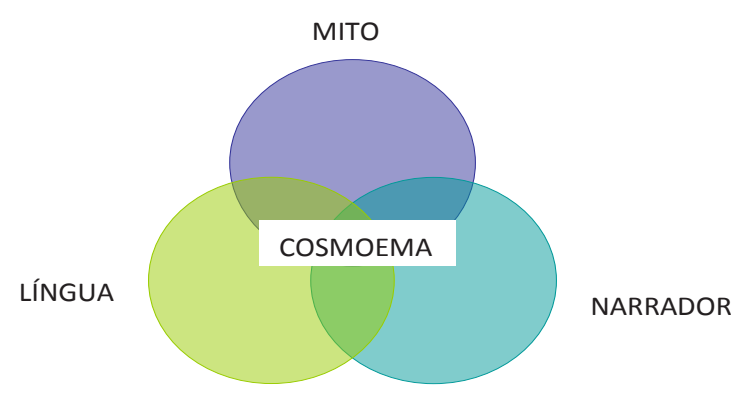

Figura 6. A análise estrutural envolvendo mito, língua e narrador

Figure 6. Structural analysis involving myth, language and narrator 
separação, mas da intersecção entre tais instâncias e o mito, conforme a proposta abaixo:

O resultado da intersecção é a unidade constituinte "cosmoema", que se configura através da atenção a estes três aspectos fundantes da etnografia da linguagem mitológica.

São Paulo, 27 de junho de 2016

\section{Referências Bibliográficas}

Abreu, C.1895. Os Bacaerys. Revista Brasileira, Ano 1, Tomos III e IV.

Bonfim, E. 2015. A Pessoa Inclusiva em Bakairi. Morfologia Pronominal e Ontologia em Línguas Karib". Espaço Ameríndio, v.9, n.1, pp.35-53.

Ducrot, O. 1987. O Dizer e o Dito. São Paulo, Pontes.

Gow, P. 2014. Mito e Mitopoiesis. Cadernos de Campo, n. 23, p. $187-210$.

Kroeber, A. L. 1909. "Classificatory systems of relationship". Journal of the Royal Anthropological Institute Vol. 39 pp:77-84.

Lévi-Strauss, C. 1996. História de Lince. São Paulo: Cia. das Letras.

Lévi-Strauss, C. 2008 [1958a]. A Estrutura dos Mitos. In: Antropologia Estrutural I. São Paulo: Cosac \& Naify.

Lévi-Strauss, C. 2008 [1958b]. A Análise Estrutural em Linguística e Antropologia. In: Antropologia Estrutural I. São Paulo: Cosac \& Naify.

Lévi-Strauss, C. 2011 [1971]. O Homem Nu. São Paulo: Cosac \& Naify.

Meira, S. 2005. Reconstructing Pre-Bakairi Segmental Phonology. Anthropological Linguistics, v. 47, n. 3, p. 261-291.
Meira, S. e Franchetto, B. 2005. The southern Cariban languages and the Cariban family. International Journal of American Linguistics, v.71, p. 127-192.

Quintino, W. P. 2012. "Aspectos da fonologia Xavante e questões relacionadas: rinoglotofilia e nasalidade". Rio de Janeiro - UFRJ. Tese (Doutorado em Linguística).

Souza, T. C. 1991. Perspectivas de Análise do Discurso em uma língua indígena: o Bakairi (Carib). Orlandi, Eni. Discurso Indígena. A Materialidade da Língua e o Movimento da Identidade. Campinas: Unicamp.

Souza, T. C. 1994. Discurso e Oralidade. Um Estudo em Língua Indígena. Tese de Doutorado apresentada ao Programa de Pós-Graduação em Linguística do Instituto de Estudos da Linguagem, Universidade Estadual de Campinas.

Souza, T. C. 1995. O Traço Sonoro em Bakairi. Wetzels, L. Estudos Fonológicos das Línguas Indígenas Brasileiras. Rio de Janeiro: Editora da UFRJ, pp. 29-52.

Souza, T. C. 1999. Discurso e Oralidade: um Estudo em Língua Indígena. Niterói: publicações do MCII/UFF.

Souza, T. C. 2006. "Alguns aspectos da ergatividade em Bakairi". Estudos da língua(gem). Vol.4, n², pp. 137-152.

Souza, T. C. 2008. "Mito e discursividade: um processo metonímico". Revista Boitatá, n 6, pp. 23-34.

Viveiros de Castro, E. 1996. "Os pronomes cosmológicos e o perspectivismo ameríndio". Mana. Estudos de Antropologia Social 2(2): 115-143.

Von den Steine, K.1892. Die Bakairi-Sprachen. Leipzig.

Wetzels, L.1997. Bakairi and the feature voice. Boletim da ABRALIN (20), 